\title{
Relectura filosófica intercultural de la obra de José Manuel Peramás
}

Philosophical intercultural rereading of José Manuel Peramás work

Alcira Beatriz Bonilla*

DOI: http://dx.doi.org/10.31057/2314.3908.v6.n2.22955

“Pro America; Pro Indis et Nigris; Pro Juventute” (J. M. Peramás ${ }^{1}$ )

Resumen: El "Descubrimiento" de América y las reacciones provocadas por el encuentro de los europeos con un "otro" que nunca había tenido cabida en su imaginario dan origen a la utopía y el ensayo. La utopía comienza con el libellus homónimo de Thomas More (1516), y se corresponden con este género tanto el texto De administratione guaranitica comparate ad Republicam Platonis commentarius, de José Manuel Peramás (1791), como el "sacro experimento" referido en él. Desde un locus enuntiationis filosófico intercultural, se realizan algunas consideraciones sobre la significación que el géne-

\footnotetext{
*Consejo Nacional de Investigaciones Científicas y Tecnológicas (CONICET) y Facultad de Filosofía y Letras, Universidad de Buenos Aires, Argentina. E-mail: alcirabeatriz.bonilla@gmail.com

${ }^{1}$ El epígrafe reproduce una intención formulada por J. M. Peramás para la celebración de la misa, que figura entre los papeles que había en su cuarto de Faenza, hallados después de su muerte en 1793, tal como lo recoge el P. G. Furlong en el "Prólogo" a la traducción al castellano de 1946 de De administratione guaranitica comparate ad Republicam Platonis commentarius.
} 
ro utópico tuvo en y para América, y una relectura analítica, breve por fuerza, de la obra mencionada, con el objeto de mostrar los límites de la interculturalidad realizada bajo condiciones asimétricas.

Palabras clave: "Descubrimiento"; utopía y ensayo; De administratione guaranitica comparate ad Republicam Platonis commentarius; interculturalidad en condiciones asimétricas de dominación

\begin{abstract}
The "Discovery" of America and the reactions of the Europeans due to the encounter with a never before imagined cultural "Other" gave rise to new philosophical genres: the utopia and the essay. The utopia begins with Thomas More's homonymous libellus (1516). Utopical are also Peramás' De administratione guaranitica comparate ad Republicam Platonis commentarius (1791), as well as the political "sacred experiment" narrated in this text -the Guaraní Missions-. On the basis of an intercultural philosophical locus enuntiationis, the autor of this article outlines some considerations on the diverse significance the utopical genre has had in America, and she provides an analytical rereading of this work, with the aim to show the limits of intercultural relationships carried out under asymmetrical conditions.
\end{abstract}

Key words: "Discovery"; utopia and essay; De administratione guaranitica comparate ad Republicam Platonis commentarius; intercultural relationships under asymmetrical conditions

Recibido: 27 de octubre de 2018 .

Evaluado: 14 de diciembre de 2018. 
Este trabajo, que amplía la ponencia "Interculturalidad, arte, evangelización y dominación. Relectura filosófica intercultural de la obra de José Manuel Peramás", leída en el Simposio 3/17 "Los jesuitas, el arte y la interculturalidad en las misiones españolas y portuguesas (siglos XVI-XVIII)", realizado en el 56 ${ }^{\circ}$ ICA el 16 de julio de 2018, se instala en un locus enuntiationis filosófico poco habitual: el de la Filosofía Intercultural "Nuestroamericana" Liberadora. Este punto de vista se considera apto para la realización de una lectura ni apologética ni detractora de uno de los textos señeros del género utópico, el conocido trabajo De administratione guaranitica comparate ad Republicam Platonis commentarius, escrito por el jesuita expulso José Manuel Peramás (17321793) en su postrer residencia de Faenza como encomio del "sacro experimento" puede considerarse la moderna concepción y creación de las "reducciones"- llevado a cabo por integrantes de la Compañía de Jesús entre los guaraníes ${ }^{3}$.

\section{El locus enuntiationis}

Si bien pueden rastrearse históricamente diversos momentos en los cuales el encuentro con "otros" culturales decantó en producciones filosóficas originales y fecundas, la Filosofía Intercultural contemporánea se remonta en tanto modo de hacer filosofía y campo de trabajo específico a los años ochenta del siglo pasado, cuando aparece como alternativa crítica a la pretensión hegemónica de la ideología de la globalización neoliberal y como búsqueda de respuestas a los desafíos que la sociedad contemporánea planteaba al trabajo filosófico. Hito fundacional de su institucionalización fue la creación de la Asociación Internacional de Filosofía Intercultural en 1991. Ram Adhar Mall, primer Presidente de la misma, señala que la Filosofía intercultural no es una corriente filosófica más, sino una actitud filosófica particular que admite que el espíritu de la filosofía se realiza en contextos culturales diferentes que pueden dialogar entre sí (Mall, $2014)^{4}$.

Decisiva para el pensamiento de "Nuestra América" fue la celebración del Primer Congreso Internacional de Filosofía Intercultural en México D.F. (1995). En esos días se incorporaron a este espacio numerosas filósofas y filósofos latinoamericanos y caribeños que le otorgaron rasgos específicos, en tanto casi en su totalidad provenían de la Filosofía de la Liberación o de otras líneas de pensamiento crítico. En atención a esta deriva latinoamericana, en la ponencia la frase que designa el locus enuntiationis de la misma recoge el adjetivo "Nuestroamericana" -de clara inspiración martiana ${ }^{5}$-, porque la misma destaca un "nosotros" específicamente "nuestroamericano" constituido por quienes se reconocen entre sí, en tanto sujetos conscientes de la propia dignidad y a la

\footnotetext{
${ }^{2}$ La expresión proviene de Das heilige Experiment, título de la obra teatral del dramaturgo vienés Fritz Hochwälter (1911-1986), estrenada en Suiza en1942, cuyo argumento se refiere a la expulsión de los jesuitas de las misiones del Paraguay.

${ }^{3}$ La autora reconoce su deuda con la excelente tesis doctoral en Etnohistoria de Mercedes Avellaneda (2014), que, al sintetizar la complejidad de los enfoques que abordan la historia de las relaciones entre guaraníes y jesuitas, le inspiró la idea de "otra" lectura posible del texto de Peramás.

${ }^{4}$ Justamente por tratarse de un talante filosófico y no de una escuela, en estos veinte años se han formado líneas muy diversas de Filosofía Intercultural, que no pueden enumerarse en esta colaboración por razones de espacio. Para una información más completa, véase, Raúl Fornet-Betancourt, 2015.

5 Como homenaje al artículo fundacional Nuestra América que José Martí publicara en 1891 (Martí 2008).
}

45 Alcira Beatriz Bonilla. Relectura filosófica intercultural ... 43-56. 
vez de la dominación colonial de la que han sido y son objeto, como bien lo ha estudiado Yamandú Acosta (Acosta, 2011).

El punto de partida de toda Filosofía Intercultural está en el factum del pluralismo de las sociedades contemporáneas que da lugar a relaciones, políticas y teorías multi- e interculturales, así como en el fenómeno actual de los nomadismos y las diásporas masivas. Sin embargo, puede asegurarse que el afianzamiento de este modo nuevo de filosofar y la ampliación de su temática en la región resultó favorecido por la coyuntura epocal de la última década del siglo pasado y la primera de éste, caracterizada por los avances de la mundialización neoliberal, la emergencia combativa de los pueblos originarios en torno a 1992 junto con la de otros grupos minorizados que luchan por el reconocimiento de sus derechos e identidades, la conciencia creciente de la "condición (neo)colonial", el incremento de constantes y pauperizados flujos migratorios, la ampliación de la crisis ambiental y de los ecosistemas, el surgimiento de formas democráticas novedosas y la constitución de bloques regionales antisistémicos, como el Mercosur y la Unasur, ahora sometidos a intentos de destrucción por parte de fuerzas conservadoras y neoliberales (Bonilla, 2017).

Para reflexionar eficazmente sobre estas cuestiones complejas, la Filosofía Intercultural propone desnaturalizar algunas nociones usuales, tales como "cultura(s)" "multiculturalismo", "interculturalidad" y "reconocimiento". Esta filosofía plantea, además, un modo de entender las culturas o "configuraciones culturales" -en expresión de Alejandro Grimson (Grimson, 2011)-, como entidades abiertas y dinámicas, situadas temporal y espacialmente, y, en consecuencia, susceptibles de cambios, intercambios, negociaciones y desaparición. En este sentido se opone a toda teoría esencialista que considere las culturas como entidades cerradas e igualmente critica las posiciones posmodernas que subestiman los entrelazamientos interculturales posibles y celebran la inconmensurabilidad e incomunicabilidad de las culturas. Otra categoría vertebral de este enfoque es la de reconocimiento. El reconocimiento intercultural posibilita diálogos, o mejor "polílogos" de hermeneusis mutua entre personas y grupos que se identifican con culturas diferentes (Estermann, 2006, pp. 28-36), aun aquéllas que han estado largamente sometidas a la "condición colonial". Para que en estos casos el diálogo intercultural prospere, se ha de hacer cargo de tal condición, vale decir, de los daños físicos, culturales, epistemológicos y morales que fueron causados al "otro" por los procesos de conquista, colonización, evangelización e imperialismo (todavía prolongados en guerras de exterminio y en diversas formas de dominación sobre poblaciones indígenas, afrodescendientes y minorizadas). Un reconocimiento tal se torna ejercicio de "reparación histórica" que ha de conceder lugar epistémico privilegiado a la pluralidad de las memorias de los pueblos y ha de asumir la responsabilidad de colaborar, para que puedan obtenerse condiciones de simetría real, las únicas que aseguran intercambios interculturales fecundos (Fornet-Betancourt, 2011, p. 32).

Según la Filosofía Intercultural, y también para algunos autores provenientes de las Ciencias Sociales Interculturales, tanto las características de los intercambios interculturales como las del polílogo filosófico posible e in fieri quedan acabadamente expresadas con la metáfora de la "traducción". En efecto, la práctica universal de la traducción (linguiística y cultural) quizá sea la operación humana que mayores intercambios ha generado, aún de manera siempre imperfecta. La Filosofía Intercultural abreva 
de modo eficaz en los estudios tradicionales y contemporáneos ${ }^{6}$ sobre traducción, porque esta metáfora señala la puesta en juego de una "hermeneusis" mutua posibilitante de polílogos racionales que, partiendo del reconocimiento de situaciones de expolio y dominación, puedan aspirar a realizarse en condiciones de simetría. De este modo no solo se contribuye a la finalización de la violencia secular, sino que por la recuperación de las memorias y los saberes subordinados o negados, la reparación histórica operada por este tipo de reconocimiento deriva en un enriquecimiento exponencial del pensamiento (Bonilla, 2016). No se trata en modo alguno de una posición ingenua que ignore la conflictividad y ambigüedad de ciertas escenas de traducción colonial y neocolonial. Por el contrario, se toma en cuenta un abanico de situaciones que va desde la actuación de los primeros trasladadores o trujimanes, pasa por la lectura del "Requerimiento" (1512) y culmina, por ejemplo, en la sabia, erudita y hábil manipulación de la lengua guaraní del P. Antonio Ruiz de Montoya, especialmente en el Tesoro de la lengua guaraní (1639) y su trabajo sobre los nombres de parentesco del Catecismo de la lengua guaraní (1640) (Ruiz de Montoya, 2011).

\section{América, "la cuestión del otro" y la emergencia del género utòpico}

Los manuales universitarios de historia de la filosofía y de teoría política otorgan poco espacio al denominado "Descubrimiento" y a la posterior conquista, colonización y evangelización del territorio americano. Sin embargo, a una mirada atenta a la historia le sobran pruebas, para sostener la idea de que tal acontecimiento constituye un hito de potencia teórica insoslayable. Merced a éste irrumpe en el pensamiento europeo nada menos que la "cuestión del otro". En efecto, lejos de producirse un "encuentro" entre grupos humanos mutuamente considerados iguales, se puso de manifiesto desde el comienzo la existencia de una relación estructural de dominación, según ha señalado Boaventura de Sousa Santos (2015, p. 141), manifestada por la asimetría que revela la construcción de un "descubierto" (el hombre americano) y un "descubridor" (el hombre europeo). Merced a esta asimetría se legitimaron todos los abusos, expolios, genocidios y matanzas. Como aporta Enrique Dussel (1994, p. 47), el "descubridor", un ego conquīro cuya figura emblemática es Hernán Cortés, resulta antepasado simétrico del ego cogito de la segunda modernidad europea con René Descartes como arquetipo.

Esta caracterización estructural, empero, no pretende una visión reduccionista del "Descubrimiento" y de sus consecuencias. ¡Cómo olvidar el ensanchamiento de los horizontes intelectuales europeos a raíz del conocimiento de culturas, religiones e idiomas hasta entonces ignorados y la renovación de los problemas filosóficos aportada por estos contactos, a los que hay que añadir la formación de un pensamiento mestizo! ${ }^{7}$. No cabe duda de que la primera gran consecuencia del Descubrimiento fue la unidad del mundo y la universalidad de la historia. Según indica P. Chaunu, comienza entonces "la mutación jamás habida del espacio humano" (Chaunu, 1969, p. XV), puesto que a partir de entonces los seres humanos pudieron conocer la Tierra en su totalidad y reconocerse como pertenecientes al mismo género.

\footnotetext{
${ }^{6}$ En este sentido es de destacar la labor del grupo salmantino "Alfaqueque", que ha desarrollado una fecunda labor teórica -incluidos trabajos historiográficos- y práctica en torno a la comunicación entre lenguas y culturas, también con la participación de filósofos interculturales (Grupo Alfaqueque, 2010 y Payàs, G. y Zavala, J. M. (Ed.), 2012).

${ }^{7}$ Consultar varios artículos de la obra dirigida por Dussel, Mendieta y Bohórquez, 2011.
} 
Consecuencia no menor del Descubrimiento fue el surgimiento temprano de dos géneros de escritura filosófica: la utopía (Fortunati, 2001, pp. 71-79) y el ensayo ${ }^{8}$. Thomas More publicó en 1516 la primera edición del Libellus vere aureus nec minus salutaris quam festivus de optimo reip[ublicae] statu, deq[ue] nova insula Vtopia, texto filosófico breve y de elegante ironía, más cercano al divertimento propio de un espíritu escogido que a las obras académicas. A partir de su edición definitiva (Basilea 1518) el género que así se inauguraba se convirtió en un producto característico del pensamiento de la Modernidad ${ }^{9}$ y desbordó sus orígenes literarios, proyectándose en ensayos concretos de tipo social o político, originando así numerosas controversias que llegan hasta hoy. Cabe sintetizar en tres rasgos la importancia de esta "pintura que habla, con el doble objeto de enseñar y deleitar", tal como la definió Philip Sidney en su Defense of Poesie (1595) (Manuel y Manuel, 1981, I, p. 15): 1) "utopía" da nombre al género, a una tendencia o forma de pensamiento específica y a formas particulares de prácticas sociales y políticas; 2) plantea el esquema clásico del género: instalado en una coyuntura político-social crítica, el autor encuentra a un viajero que le describe en detalle la estructura de un país inventado; 3) el término se constituye en "agenda del mundo moderno"10, determinando la investigación filosófico-política y orientando formas de la práctica política para casi quinientos años.

Además, la Utopía hace patente el estímulo que el Descubrimiento significó para el pensamiento europeo. Siguiendo a Franz y Fritzie Manuel, se defiende aquí la idea de que la utopía occidental moderna es una "planta híbrida" que brotó en el Renacimiento (Manuel y Manuel, 1981, I, o. 33). En opinión de la autora de este artículo -que completa la de estos especialistas-, así como las de Krisan Kumar (1981) y Paul Moreau (1986), su aparición y primer desarrollo se debió a la conjunción feliz operada desde la racionalidad moderna en formación del redescubrimiento de los clásicos con la lectura apasionada de los primeros escritos sobre el Nuevo Mundo, sin olvidar el suelo común de las creencias paradisíacas, milenaristas y mesiánicas judeo-cristianas y la práctica de la vida monástica. En suma, un género filosófico intercultural sui generis, si cabe. Volviendo al caso de More, resultó decisiva la influencia del llamado "evangelismo" cristiano en su versión erasmiana, movimiento de retorno a las fuentes cristianas primitivas en clave humanista. A esto hay que añadir la difusión del corpus platónico que también alimentó la confianza en la posibilidad de una organización racional de la vida social y política en términos más mundanos que los proporcionados por la teología desde San Agustín. Para la mayor parte de los investigadores, sin embargo, ha pasado desapercibido el papel que desempeñó el Descubrimiento de América como disparador de la utopía. Varios americanistas y algo más tarde algunos filósofos y filósofas nuestroamericanos destacaron el choque experimentado por los pensadores ante una América que se iba revelando a través de los escritos de Cristóbal Colón, Américo Vespuccio y otros, por más que se tratara de un acontecimiento preanunciado y esperado largamente, con huellas profundas en el imaginario europeo.

\footnotetext{
${ }^{8}$ Aunque no es tema de este trabajo, vale la pena señalar que, contra de la opinión habitual que sitúa la aparición del ensayo en 1580, fecha de la primera entrega de los Essais de M. de Montaigne, Fernando Aínsa adelanta el inicio de este último género a 1511, cuando F. Antón de Montesinos pronunció su primer sermón de Navidad contra los encomenderos, y lo caracteriza como un género privilegiado para la transmisión de ideas ético-políticas de Nuestra América (Aínsa, 2005, pp. 239-240).

${ }^{9}$ Valga como dato de la popularidad del género que más de veinte "utopías" fueron publicadas durante el siglo XVI y fueron inspiradoras de prácticas sociales y políticas.

${ }^{10}$ La expresión pertenece a K. Kumar (1981).

48 Alcira Beatriz Bonilla. Relectura filosófica intercultural ... 43-56.
} 
El título abreviado de Utopía responde al carácter alegórico del texto y sirve como muestra inicial del proceder de More para designar localidades, nombres de personas, accidentes geográficos, funcionarios, etc., mediante neologismos de origen griego discretamente humorísticos que despertaran ecos prestigiosos en sus lectores. Utopía -compuesto de ou ("no") y tópos ("lugar")- designa la isla que servirá de escenario para la parte más importante del relato y cuyo carácter ficticio se refuerza por el empleo del topónimo elegido. Para entender los procedimientos narrativos de More y algunas de sus consecuencias geopolíticas posteriores, interesa el dato de que Utopía sea una isla. More, de modo imaginario, ha a-islado (convertido en una isla) a un grupo humano, para hacer con él un experimento mental decisivo. Empleado tanto por los filósofos de lo político como por los creadores de la ciencia moderna de la naturaleza, el recurso a experimentos racionales es índice de la modernidad del pensamiento de More. Del mismo modo que el comportamiento de un cuerpo o de un elemento sometido a condiciones especiales (ideales) en el experimento físico, químico o biológico permite estudiar los comportamientos naturales y extraer sus leyes, pero es diferente del que se da en la realidad no sometida a estas condiciones artificiales, la utopía jamás se realiza: "el no-lugar no puede tener un lugar ni tener lugar" (Giroux, 1985, p.23) ${ }^{11}$. Esto mismo la vuelve más dinámica: desde la utopía (el "buen lugar", Eutopía) se puede ejercer la crítica de una sociedad dada y avistar las condiciones de su cambio.

Según José Luis Abellán, More mismo se dio cuenta de la íntima conexión entre la utopía de raíz erasmista y América (1992, p. 181). Primera evidencia de ello es la figura del narrador principal, Rafael Hythlodaeo, quien se presenta como un marino portugués con rasgos de filósofo humanista y compañero de los tres últimos viajes de Vespucio. No se sabe bien dónde, pero la isla Utopía está en algún lugar del Nuevo Mundo cuya localización han olvidado preguntar al viajero tanto More como P. Egidio (More, 1996, p. 2). El relato de Hythlodaeo resulta confuso: impreciso el puerto en el que se despiden de Vespuci y, más desdibujado aún, el itinerario difícil y riesgoso desde la salida de Utopía a través de paisajes y ciudades de latitudes diversas. Más adelante se repite la referencia al Nuevo Mundo ya en términos de valoración positiva con respecto a la costumbre europea de realizar pactos para luego violarlos, a lo que añade el desprecio por el oro, el comunismo de bienes, la sencillez de las costumbres, cierto hedonismo natural, la igualdad sexual. Todos rasgos de la imagen del "buen salvaje" que More recuperó de los textos de los viajeros. Aunque sin ubicación precisa en la representación del globo terráqueo que lentamente se va construyendo en la época, el "no-lugar" se manifiesta como espacio americano, tierra sin mal de los orígenes donde los sueños de justicia imposibles ya en el viejo continente podrían tener cabida (obviamente, haciendo caso omiso de los "naturales" o evangelizándolos). Un rasgo más de esta modernidad moreana, según P. Moreau, es la puesta en circulación en forma imaginaria de la teoría del derecho natural basándose en "una concepción igualitaria del sujeto jurídico por medio de esta ideología técnica del estado" (Moreau, 1986, p. 134).

Con la filósofa española María Zambrano puede afirmarse que la nostalgia y la esperanza son las dos fuerzas del corazón humano que constituyen la matriz utópica de la historia (Zambrano, 1991). Sin embargo, cabe una pregunta fundamental: América, o mejor su pretendido "descubrimiento", resulta disparador del género y de las prácticas utópicas, pero ¿dónde queda ella misma, sus habitantes, su tierra, una vez convertida en continente utópico por excelencia? Sin duda, la nostalgia del Paraíso perdido, de los

${ }^{11}$ Traducción de la autora.

49 Alcira Beatriz Bonilla. Relectura filosófica intercultural ... 43-56. 
Lugares Santos, de míticas ciudades e Islas Bienaventuradas y la esperanza de encontrarlas estuvieron en la base de la manía descubridora de Colón; pero provocando a la vez la serie de "encubrimientos" con los cuales el hombre europeo ocultó las diferencias, la "ajenidad" u "otredad" de América. Paraíso, lugar de la utopía o simplemente caos (Scheines, 1991), América será el espacio que los europeos pretendan arcilla, virtualidad pura, sin lenguas, sin tradición y sin historia, pero al mismo tiempo lugar propicio para realizar los deseos no cumplidos en el Viejo Continente (Bonilla, 2004 y 2010; Cerutti G., 1989, pp. 111-119). El descubrimiento del "otro", como señala Aínsa, fue en realidad una nueva invención de sí mismo: Europa "renace" y se "redescubre" en sus utopías americanas (Aínsa, 1999). Dejando de lado listados y cronologías demasiado extensas, baste señalar la existencia de dos linajes que se desprenden de Utopía y llegan hasta hoy: uno que puede denominarse colonialista (y no colonial, porque excede en el tiempo el período histórico de ese nombre y tuvo y tiene manifestaciones tardías) donde el "otro" nuestro americano carece de lugar propio o, si tiene alguno éste es de subordinación y aceptación pasiva, y un linaje que puede denominarse "decolonial", porque en tales textos y realizaciones utópicas, como dice Aínsa, se manifiesta la aspiración de una sociedad alternativa a la dada, la invención de una sociedad en la cual "saber vivir" con y para el otro en el marco de instituciones justas sea más importante que "saber hacer" o, como señala la Filosofía de la Liberación, donde las víctimas puedan llegar a ser sujetos históricos de pleno derecho o, como propugna la Filosofía Intercultural, donde el reconocimiento del "otro" pueda aspirar a darse en un polílogo intercultural en condiciones de simetría social, económica y política.

\section{EI "sacro experimento" de las reducciones guaraníticas y la interpretación utópica de J. M. Peramás}

Veinticinco años después de la aparición de Utopía se creaba la Compañía de Jesús, en 1585 se fundó el Colegio de los jesuitas en Asunción y en 1609 el P. Marcial Lorenzana fundó la primera reducción de San Ignacio Guazú que tuvo como antecedente la labor evangélica de F. Luis Bolaños ${ }^{12}$. El "sacro experimento" jesuítico de las misiones o reducciones del Paraguay tuvo justamente como una de sus características un doble "aislamiento": por una parte, geográfico, jurisdiccional y étnico, con la erección de poblados siguiendo las normas de la Corona, pero separados del resto tanto por su modo de organización como por su composición étnica. Además se dio un aislamiento linguiístico, con el escaso uso del castellano y la preservación del idioma guaraní mediante la escritura y su empleo cotidiano de acuerdo a una interpretación favorable al catolicismo contrarreformado y a la acción misional. Como señalan varios autores contemporáneos, tal aislamiento muchas veces fue más deseado que real y no pudo darse de modo acabado, puesto que los guaraníes nunca se comportaron como meros objetos de experimentación, sino que fueron agentes históricos activos, con resistencias y contra-

\footnotetext{
${ }^{12}$ La herencia de Francisco de Asís, el milenarismo joaquinita y las utopías nuevas, especialmente la de Moro (terciario franciscano) estuvieron en la raíz del estilo franciscano de la evangelización americana iniciada en 1524. Testimonio de esto, entre muchos, es el de Vasco de Quiroga en su Información en Derecho (1535) al Consejo de Indias sobre las Juntas Eclesiásticas de 1532 donde manifiesta gran reverencia por la Utopía de Moro, el cual, dice, “como inspirado del Espíritu Santo, sacó las ordenanzas y muy buen estado de república... de donde como de dechado se sacó mi parecer” (Gil, 1993, p. 198).
} 
dicciones en su relación con los Padres, los encomenderos y los funcionarios virreinales ${ }^{13}$.

Se destaca que este modo de concebir las reducciones no sólo se encontraba relacionado con la idea de una acción encaminada a la conversión de los nativos al catolicismo -obviamente considerados "infieles"-, sino que deriva igualmente de una representación política y cultural de la empresa misional. En lo político las reducciones guaraníes sirvieron para extender los dominios de la Corona sobre pueblos particularmente belicosos, así como para frenar apetencias criollas de autonomía y contener los avances de los bandeirantes sobre el territorio. Pero los Padres fueron más lejos. Obedientes a la normativa del Segundo Concilio de Lima (1567), mediante la organización del sistema de reducciones ${ }^{14}$ combatieron tenazmente el nomadismo -en la época casi siempre identificado con salvajismo-, porque comprendieron, según señala G. Wilde, que "lo que estaba en juego era un concepto de "civilidad"' (Wilde, 2009, p.51). De allí la necesidad del establecimiento de una vida urbana y cristiana (un "buen ser") opuesta al sistema antiguo (un "mal ser"), de la racionalización y la ritualización de los espacios y los tiempos del trabajo, el descanso, el culto y las fiestas, de la vigilancia y el control de todos los aspectos de la vida. En suma, se trató de una empresa de conversión cultural total.

La expulsión de los jesuitas de España y sus dominios (1767) y la supresión de la Societas Iesu (1773) no produjo mengua significativa en el impulso utópico que siempre alentó su labor misionera. Entre otras, resultan ejemplares las figuras de dos jesuitas expulsados de América: el P. José Manuel Peramás (1732-1793), que vivió durante su destierro en Faenza, y el P. Manuel de Lacunza y Díaz (1731-1801). A entender de la autora de este artículo, estas dos figuras resultan emblemáticas del aserto antes citado de M. Zambrano: Peramás hace de su nostalgia un arma retórica contra los enemigos de la utopía misionera, en tanto el melancólico Lacunza, que muere ahogado en Ímola en circunstancias algo confusas, convierte su nostalgia en una interpretación esperanzada y milenarista de las Sagradas Escrituras con vasta y subterránea influencia sobre los movimientos independentistas de Nuestra América. Baste recordar que el general Manuel Belgrano financió en 1816 la edición londinense en castellano de La venida del Mesías en gloria y magestad.

En los momentos particularmente dramáticos del exilio y en primera persona del plural ("es bueno que nos escuchen con paciencia, ya que no con agrado", (Peramás, 1946, p. 190)), J.M. Peramás ${ }^{15}$-jesuita que había estado en las Misiones y fue expulsado del Colegio de Córdoba ${ }^{16}$ - escribió en clave utópica ${ }^{17}$ como apología del "sacro experi-

${ }^{13} \mathrm{Al}$ respecto, véase el trabajo de M. Avellaneda, ya citado, y el libro de G. Wilde (2009).

${ }^{14}$ Los tres primeros capítulos de la obra que aquí se comenta tratan este tema de modo especial.

${ }^{15}$ Siendo "el más prolífico biógrafo del siglo XVIII”, según sostiene C. Page (2011b, p. 32), Peramás escribe De administratione guaranitica comparate ad Republicam Platonis commentarius como parte de su obra De Vita et moribus tredecim virorum paraguaycorum (1793). Las citas textuales de este trabajo están tomadas de la traducción al castellano publicada en Buenos Aires en 1946, que figura en las Referencias Bibliográficas, no teniendo la autora disponible para establecer comparaciones la traducción publicada en 2004 por Francisco Fernández Pertíñez y Bartomeu Melià (Asunción: Centrode Estudios Paraguayos Antonio Guasch).

${ }^{16}$ Las vicisitudes de la expulsión y viaje hasta su destino final en Faenza están contenidas en el Diario del destierro, que abarca una relación de los hechos desde el 11 de julio de 1767 hasta el 24 de setiembre de 1768. Las citas y datos del mismo se toman de la obra de C. Page, 2011a.

51 Alcira Beatriz Bonilla. Relectura filosófica intercultural ... 43-56. 
mento" De administratione guaranitica comparate ad Republicam Platonis commentarius (1793). La apelación a Platón en el título y a lo largo del texto opera sobre todo como un recurso retórico prestigioso que por su mera mención facilita el encomio, pero que también indica un deber y un desiderátum propios del pensamiento clásico (que la "república cristiana" ha de superar con creces). En virtud de esto Peramás llega a identificar América con la Atlántida platónica, puesto que en esas obras se encuentran "algunos vestigios concretos de América", señalando más adelante: "tanta es la correspondencia de lo allí narrado con lo descubierto posteriormente” (Peramás, 1946, p. 114).

Ex post facto (autorizado por la propia experiencia y la consulta de documentos y textos sobre el tema) se propone el objetivo de investigar, si existió "alguna vez en el mundo" la república platónica, dando por descontado que podrá probar la hipótesis que preside el texto: "abrigamos la esperanza de poder demostrar que entre los indios guaraníes de América se realizó, al menos aproximadamente, la concepción política de Platón" (Peramás, 1946, pp. 19-20). Tal objetivo es perseguido mediante una exposición metodológicamente planteada en tres partes: una síntesis crítica del pensamiento platónico sobre el tema que toma como referencias principales República y Leyes -"lo que se practicaba entre los guaraníes"- y un espacio para el lector: "finalmente el lector juzgará si entre las normas de aquél y las prácticas de éstos había similitud o discrepancia" (Peramás, 1946, p. 20). Pero no se trata de la organización político social de los guaraníes, que en varios pasajes de sus obras son calificados de modo ambiguo, muchas veces inferiorizante, sino de la obra de los Padres de la Compañía por y con los guaraníes. En este sentido puede afirmarse que las reducciones constituyeron un caso particular de relaciones interculturales que se desarrollaron en condiciones de asimetría. La intención de Peramás va más allá de Platón, porque describe una posible república cristiana en el Nuevo Mundo que pudo darse, en virtud del aislamiento territorial y lingüístico impuesto por los jesuitas, gracias a la contaminación escasa de los indígenas "reducidos" con los hombres y prácticas del Viejo. Esta intención apologética se plasma a lo largo de veintisiete capítulos en los que simplemente "espiga" algunos temas aptos tanto para el establecimiento de la comparación como para confirmar la intención que la preside.

Lejos de ser el pretendido estudio comparativo entre el diseño platónico y la organización y vida de las reducciones, la obra es reveladora de la forma final en la que quedaron plasmadas, además de la experiencia concreta de los Padres, la influencia de tradiciones indígenas, de las Leyes de Indias, de la teología jesuítica y de la impronta utópica, todo ello realzado con la consulta erudita de fuentes de procedencia dispar. Hombre de la Contrarreforma e ilustrado, Peramás aborda el pensamiento platónico de manera metódica y críticamente, movido por un afán apologético y misional. En esto se diferencia de T. More a quien, empero, cita elogiosamente y con carácter de autoridad respecto de la práctica de la agricultura en las Misiones: "Esto lo hubiera aprobado, sin duda, el célebre Tomás Moro, quien deseaba que todos los integrantes de su república Utopía fuesen agricultores" (Peramás, 1946, p. 48). También está más cerca de More que de Platón en otros temas como la práctica de la comunidad de bienes, el trazado geométrico de los pueblos, el respeto por la lengua vernácula (guaraní), el ordenamiento familiar, etc. Texto indispensable para un estudio filosófico y político de las reducciones guaraníticas, no guarda empero la distancia con la realidad que le hubiera permitido dar

\footnotetext{
${ }^{17} \mathrm{Si}$ bien el texto refiere a hechos del pasado, aquí se sostiene su carácter utópico y no ucrónico del mismo, si bien podría considerársela una "eucronía", al menos en la óptica de su autor; vale decir, un relato de los "buenos tiempos", con carácter ejemplar.
}

52 Alcira Beatriz Bonilla. Relectura filosófica intercultural ... 43-56. 
cuenta de la contradicción latente en la empresa jesuítica, contradicción que fue tal vez motivo de la ruina conjunta de las Misiones y de sus mentores.

A más de dos siglos de estos hechos, en su libro El guaraní conquistado y reducido, el etnohistoriador jesuita Bartomeu Meliá pondera adecuadamente el carácter no conservador y la ambigüedad de este intento que puso en cuestión el sistema colonial:

"Las reducciones fueron utopía anticolonial, pero no llegaron a ser política real contra la colonia. Las reducciones, disfuncionales dentro del sistema, no se atrevieron a atacar al sistema colonial en sus mismas raíces. Este fue el drama de la expulsión de los jesuitas que tuvieron que obedecer al sistema en contra de un ideal de justicia a favor de los indios que sólo pudo ser realizado a medias, y que al fin se volvió contra los indios y jesuitas a la vez" (Meliá, 1993) ${ }^{18}$.

Para concluir, con una brevísima reflexión desde la Filosofia Intercultural Nuestroamericana Liberadora: siguiendo al sabio Bertomeu Melià, puede estimarse que el fracaso de las reducciones obviamente se debió al conflicto entre los objetivos de la Corona y los del ideal de justicia enarbolado por los Padres. Sin embargo, tal vez se pueda ir más allá de la evocación nostálgica y necesariamente apologética, para señalar que este tipo de realización utópica, con toda la grandeza y sacrificios "pro Indis" que realizaron los jesuitas, estuvo imbuida de un sesgo colonialista y pertenece al subgrupo que tomó en cuenta el "buen natural" de los indígenas al que pretendió imponer modelos políticos y de convivencia justa ajenos -total o parcialmente-, que los subalternizaron y, por consiguiente, estaban destinados al fracaso. No obstante estas críticas, el escrito del P. Peramás, lejos de ser una utopía más de los miles que se han escrito, estimula el deseo de un mundo alternativo y no estaría del todo desacertado ponerlo también más cerca de las utopías que en Nuestra América se han apropiado del género y han alentado esperanzas de liberación.

\section{Referencias Bibliográficas}

Abellán, J. (1992). El pensamiento renacentista en España y América. En L. Robles (Ed.), Filosofía Iberoamericana en la época del Encuentro. Madrid, España: Trotta, pp. 155-191.

Acosta, Y. (2011). Reflexiones desde "Nuestra América". Estudios latinoamericanos de historia de las ideas y filosofía de la práctica. Montevideo, Nordan-Comunidad. (2017). "Interculturalidad y transición a la transmodernidad". Conferencia. I Jornada de Filosofía Intercultural, Facultad de Filosofía y Letras, Universidad de Buenos Aires, Buenos Aires, Argentina, 7 de diciembre de 2017 (inédita; edición en preparación).

Aínsa, F. (1999). La reconstrucción de la utopía. Buenos Aires, Argentina: Ediciones del Sol.

${ }^{18}$ La cita está tomada de la versión que figura en :

http//www.portalguarani.com/807_bartomeu_melia_lliteres/13185_el_guarani_conquistado_y_reducido_ 1993_ensayos_de_bartomeu_melia.html

53 Alcira Beatriz Bonilla. Relectura filosófica intercultural ... 43-56. 
(2005). Ensayo. En R. Salas Astrain (Coord.), Pensamiento Crítico Latinoamericano, conceptos fundamentales. Santiago de Chile, Chile: Ediciones Universidad Católica Silva Henríquez, Vol. I, pp. 239-265.

Avellaneda, M. (2014). Guaraníes, criollos y jesuitas. Luchas de poder en las Revoluciones Comuneras del Paraguay, siglos XVII y XVIII. Asunción, Paraguay: Academia Paraguaya de la Historia y Tiempo de Historia.

Bareiro Saguier, R. y Duviols, J.-P. (Ed.) (1991). Tentación de la utopía: las Misiones jesuiticas del Paraguay. Prólogo de A. Roa Bastos; Introducción de R. Bareiro Saguier y J.-P. Duviols. Barcelona, España: Tusquets / Círculo.

Bohórquez, C. (2005). "Utopía” en Salas Astrain, R. (Coord.), Pensamiento Crítico Latinoamericano, conceptos fundamentales, Santiago de Chile, Ediciones Universidad Católica Silva Henríquez, Vol. III. pp. 1033-1039.

Bonilla, A. (1993). El pensamiento latinoamericano y las celebraciones del V Centenario. Heteroglossia. Macerata, Italia, 5, pp. 13-29.

(2003). Filosofía y utopía en América Latina / Philosophy and Utopia in Latin America. En M. Lobosco (Comp.), La resignificación de la ética, la ciudadanía y los derechos humanos en el siglo XXI. Buenos Aires, Argentina: EUDEBA, pp. 177-190 / 409-422.

(2004). La Utopía de Tomás Moro y el Descubrimiento de América. Nuestra Historia. Buenos Aires, Argentina, V. XXXI, 51, pp. 5-34.

(2010). Filosofía y violencia. Cuadernos-FHYCS-UNJu. Violencia: Sentidos, Modelos y Prácticas. San Salvador de Jujuy, Argentina, 38, pp. 15-40.

(2916) Los alcances de la metáfora de la traducción en la Filosofía Intercultural. Actas. II Jornadas Nacionales de Filosofía. Buenos Aires, Argentina:Departamento de Filosofía, FFyLL UBA (e/p).

(2017). La Filosofía en el cambio de época: desafíos y propuestas. Cuadernos FHyCS-UNJu. San Salvador de Jujuy, Argentina, 51, pp. 39-48.

Cerutti Guldberg, H. (1989) Peripecias en la construcción de nuestra utopía. En: L. Zea (Com.), El descubrimiento de América y su sentido actual, México: Instituto Panamericano de geografía e historia / FCE, pp. 111.119.

Chaunu, P. (1969). Conquête et exploitation des nouveaux mondes, xvi e.s. Paris, Francia: PUF.

Dussel, E. (1994). 1492: el encubrimiento del otro: hacia el origen del mito de la modernidad. La Paz, Bolivia: UMSA / Plural Editores.

(2004). Sistema mundo y transmodernidad. En: S. Dube, I. Banerjee y W. Mignolo (Ed.), Modernidades coloniales, México: El Colegio de México.

Mendieta, E y Bohórquez, C. (Ed) (2011). El pensamiento filosófico latinoamericano, del Caribe y “latino” [1300-2000], México, Siglo XXI.

Estermann, J. (2007). Filosofía andina. Sabiduría indígena para un mundo nuevo. La Paz, Bolivia: ISEAT. 
Fornet-Betancourt, R. (2009). Tareas y propuestas de la Filosofía Intercultural. Aachen, Alemania: Wissenschaftsverlag Mainz in Aachen.

(2011). La Filosofía Intercultural y la dinámica del reconocimiento. Temuco, Chile: Ediciones UC Temuco.

(Dr.) (2015). (Hrsg.) (2015) Zur Geschichte und Entwicklung der Interkulturellen Philosophie. Aachen, Alemania: Wissenschaftsverlag Mainz in Aachen.

Fortunati, V. (2001). Scrittura di viaggio e scrittura utópica. En V. Fortunati y O. Steimberg (Comp.), El viaje y la utopía, Buenos Aires, Argentina: Atuel, pp. 7179.

Furlong, G. (1947). Nacimiento y desarrollo de la filosofía en el Río de la Plata. 15361810. Buenos Aires, Argentina: Kraft.

Gil, F. (1993). Primeras 'Doctrinas' del Nuevo Mundo. Estudio histórico-teológico de las obras de Fray Juan de Zumárraga (+1548), Buenos Aires, Argentina: Publicaciones de la Facultad de Teología de la Universidad Católica Argentina.

Giroux, L. (1985). L'utopie: naissance, croissance, mort... et résurrection. En G. Bouchard, et alii, L'Utopie aujoud'hui. Montréal, Canadá: Les Presses de l'Université de Montréal / Les Éditions de l'Université de Sherbrooke, pp. 1783.

González, R. (2014). La Compañía de Jesús y la renovación de la iconografía ornamental en el sur andino. Migraciones y rutas del barroco, VII Encuentro internacional sobre barroco. La Paz, Bolivia.

Grimson, A. (2011). Los límites de la cultura. Críticas de las teorías de la identidad. Buenos Aires, Argentina: Siglo XXI.

Grupo Alfaqueque (2010). Los límites de Babel. Ensayos sobre la comunicación entre lenguas y culturas. Madrid / Frankfurt a. M.: Iberoamericana / Vervuert.

Kumar, K. (1981). Utopianism. Minneapolis, U. S.: University of Minnesota Press.

Mall, R. (2014). Intercultural Philosophy: A Conceptual Clarification. Confluence. Online Journal of World Philosophies. Munich, Alemania. 1, 67-84.

Manuel, F. y Manuel, F. (1981). El pensamiento utópico en el mundo occidental, Madrid, España: Taurus.

Martí, J. (2008). Nuestra América. Caracas, Venezuela: Biblioteca Ayacucho.

Meliá, B. (2011). La filosofía guaraní. En E. Dussel, E. Mendieta y C. Bohórquez, C. (Ed.) El pensamiento filosófico latinoamericano, del Caribe y "latino" [13002000], México: Siglo XXI, pp. 46-51.

(1993). El guaraní conquistado y reducido. Ensayos de Etnohistoria. Asunción, Paraguay: Universidad Católica "Nuestra Señora de la Asunción".

More, T. (1967). Utopia. Translation with an introduction by P. Turner. London, United Kingdom: Penguin.

Moreau, P. (1986). La utopía. Derecho natural y novela del Estado. Buenos Aires, Argentina: Hachette. 
Moro, T. (1996). Utopía. Estudio preliminar de A. Poch, traducción y notas de E. García Estébanez. 3.ed. Madrid, España: Tecnos.

Page, C. (2011a). Relatos desde el exilio. Memorias de los jesuitas expulsos de la antigua provincia del Paraguay. Asunción del Paraguay, Paraguay: Servilibro. (2011b). Siete ángeles. Jesuítas en las reducciones y colegios de la antigua provincia del Paraguay. Buenos Aires, Argentina: SB.

Payàs, G. y Zavala, J. M. (Ed.). La mediación lingüístico-cultural en tiempos de guerra: miradas desde España y América, Temuco, Chile: Ediciones Universidad Católica de Temuco.

Peramás, J.M. ([1791] 1946). La República de Platón y los guaraníes. Trad. J. Cortés Del Pino. Pról. G. Furlong. Buenos Aires, Argentina: Emecé.A.

Ruiz de Montoya, A. ([1639-1640] 2011). Arte, Vocabulario, Tesoro y Catecismo de la lengua guaraní. Publicado por B. Melià S.I. IV Tomos. Asunción, Paraguay: Centro de Estudios Paraguayos "Antonio Guach".

Salas, R. (2012). Reconocimiento, traducción y conflictividad. Las siempre conflictivas y nunca acabadas relaciones con los otros. En G. Payàs y J. M. Zavala (Ed.), $L a$ mediación lingüístico-cultural en tiempos de guerra: miradas desde España y América. Temuco, Chiles: Ediciones Universidad Católica de Temuco, pp. 123138.

Santos, B. (2005). El milenio huérfano. Ensayos para una nueva cultura política, Madrid, España / Bogotá, Colombia: Trotta / ILSA.

Scheines, G. (1991). Sudamérica ¿geografía del desencuentro? La Habana, Cuba: Casa de las Américas.

Wilde, G. (2009). Religión y poder en las misiones de guaraníes. Buenos Aires, Argentina: $\mathrm{Sb}$.

Zambrano, M. (1991). El hombre y lo divino. 2 ed. Madrid, España: Siruela. 